\title{
Wild Edible Plants as Potential Antioxidants in Vegetables Oils
}

\author{
Ana Romojaro, ${ }^{1}$ Paloma Sanchez-Bel, ${ }^{2}$ Maria Serrano, ${ }^{1}$ and M. Teresa Pretel ${ }^{1}$ \\ ${ }^{1}$ Departamento Biología Aplicada, Escuela Politécnica Superior de Orihuela, Universidad Miguel Hernández, \\ Ctra Beniel-Orihuela, km 3.3, 03312 Alicante, Spain \\ ${ }^{2}$ Departamento Biología del Estrés y Patología Vegetal, Centro de Edafología y Biología Aplicada del Segura, CSIC, \\ Espinardo, Murcia, Spain
}

Correspondence should be addressed to M. Teresa Pretel; mteresa.pretel@umh.es

Received 10 September 2013; Accepted 14 November 2013

Academic Editor: Hamadi Attia

Copyright (C) 2013 Ana Romojaro et al. This is an open access article distributed under the Creative Commons Attribution License, which permits unrestricted use, distribution, and reproduction in any medium, provided the original work is properly cited.

\begin{abstract}
The effect of the addition of fruits of Rosa canina and Quercus ballota and leaves of Sanguisorba minor to sunflower, seed, and olive oils on lipid oxidation during the frying process was analyzed. The three underutilised edible plants increased the oxidative stability of the sunflower oil, since the malondialdehyde (MDA) content was significantly decreased with respect to values of the control sunflower oil after the heating process. However, in olive oil, the effect of these edible plants on decreasing the lipid peroxidation was only evident for the highest concentration, while in seed oil the addition of the edible plant showed a prooxidant effect. Thus, these wild edible plants could be used to enrich vegetable oils with low content of natural antioxidant, such as sunflower oil, and avoid or decrease the use of synthetic antioxidant.
\end{abstract}

\section{Introduction}

Edible vegetable oils such as sunflower oil, seed oil, and olive oil have an important place in human diet, since their use in culinary processes is a constant. However, during frying, a gradual deterioration of oil quality occurs due to lipid oxidative decomposition reactions leading to lowering quality and nutritional value of foods, with consequences for the health of the consumer, causing aging, membrane damage, and numerous diseases, such as chronic inflammation, neurodegenerative diseases, adult respiratory distress syndrome, atherogenesis, diabetes, and different types of cancer [1]. Synthetic antioxidants, such as butylated hydroxyanisole (BHA), butylated hydroxytoluene (BHT), and tertbutyl hydroquinone (TBHQ), are widely used in the food industry to avoid oxidation [2] due to their low cost and good performance, although their safety has been questioned due to carcinogenic effect [3]. According to the European Bulletin (order of 24 August 2007) [4] the maximum dose that allowed for these artificial additives in frying oils is $200 \mathrm{mg} \mathrm{kg}^{-1}$ of oil.

Under these circumstances, research on development of safe natural antioxidants is therefore essential. Recently it has been shown that Nigella sativa seed extract could be an interesting alternative to the use of synthetic antioxidants, since the addition of Nigella seed extract to sunflower oil improved their thermal stability and shelf-life [5]. Accordingly, Cordeiro et al. [6] have shown that extract of Rosmarinus officinalis added to sunflower, corn, and soybean oils displayed a more effective antioxidative action than TBHQ and it was stable at the frying temperature of the oils, unlike the majority of the antioxidants commonly used. Moreover, even in olive oils which contain high concentration of natural antioxidants, the addition of oregano essential oils leads to a protective effect on primary lipid oxidation [7].

Recent phytochemical studies have revealed that fruits from Rosa canina L. contain high amounts of vitamin C, carotenoids, and polyphenols making them a suitable source of antioxidants to be used commercially to retard rancidity in fatty materials in food manufacturing $[8,9]$. Accordingly, acorns from Quercus spp. also possess biologically active substances, such as $\alpha$ - and $\gamma$-tocopherol and phenolics compounds, specially tannins, with proved antioxidant and free-radical-scavenging capacities [10, 11]. Finally, leaves and shoot from Sanguisorba minor Scop. (Sm) have also high 


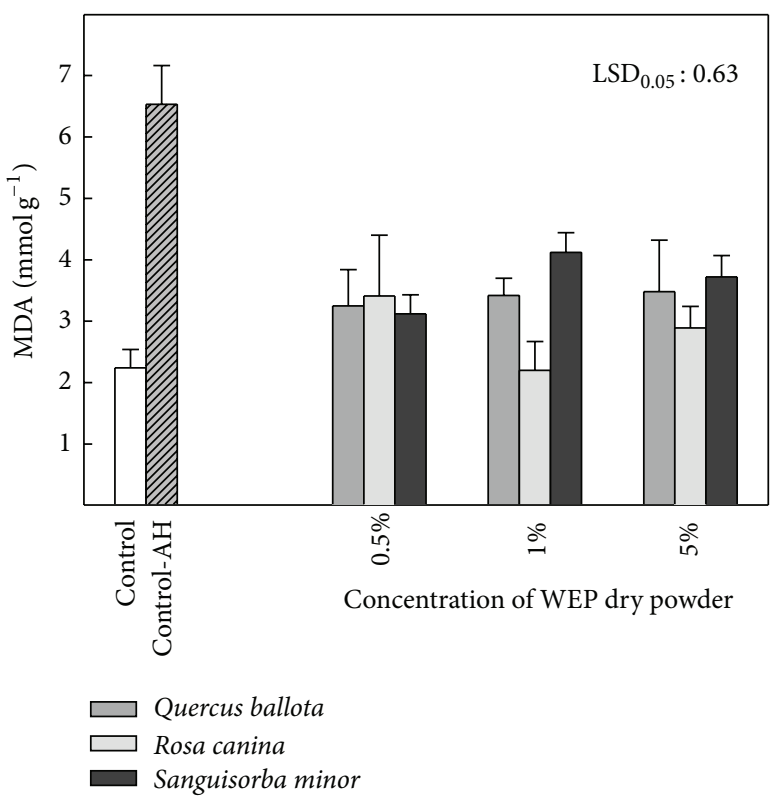

(a)

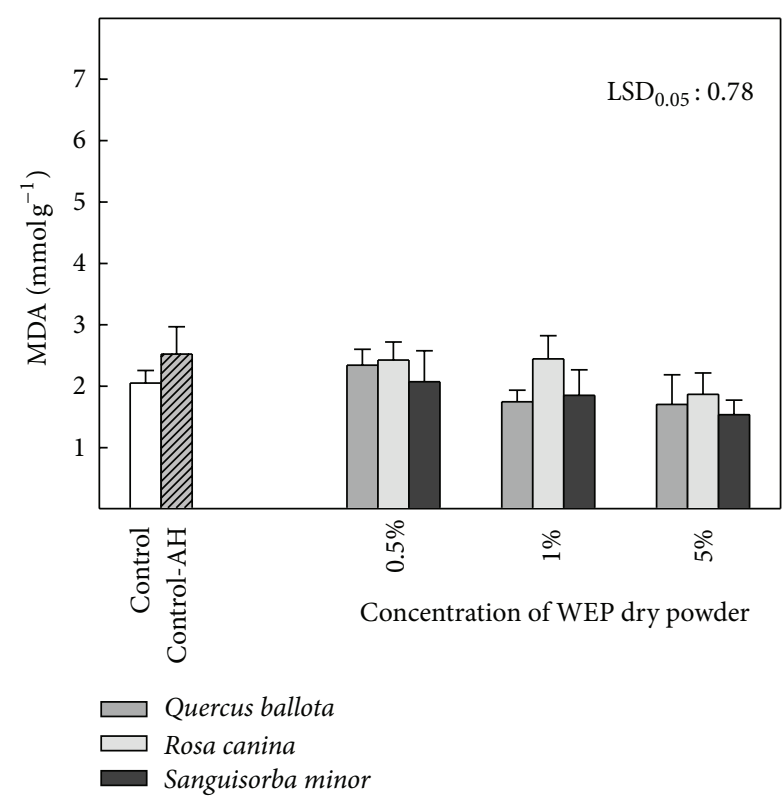

(b)

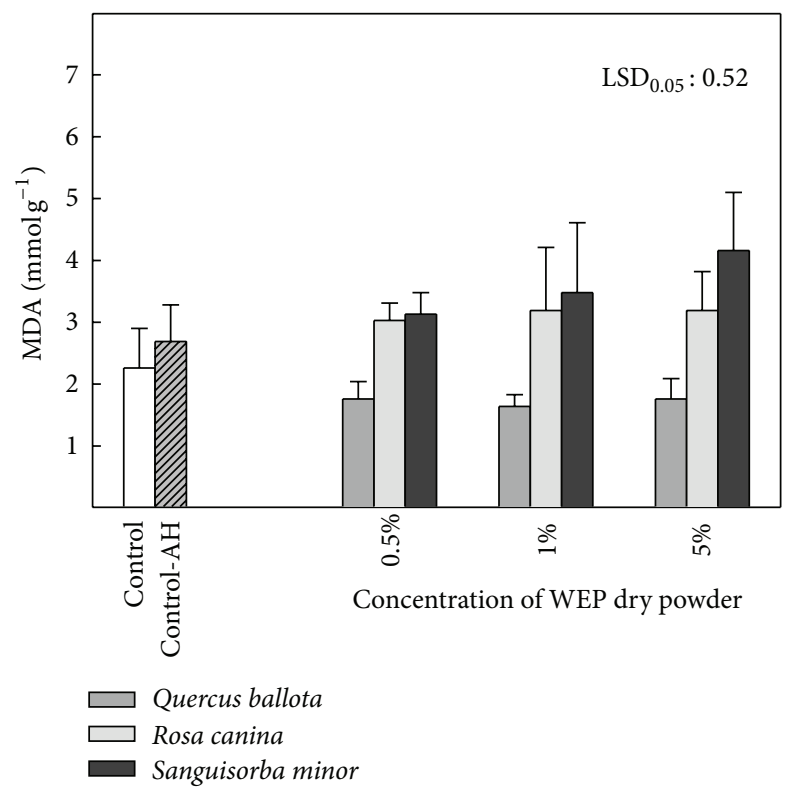

(c)

FIGURE 1: Lipid peroxidation value, expressed as malondialdehyde (MAD) concentration, in vegetable oils before the heating process (control) and after heating $(\mathrm{AH})$ and after the heating process of these edible oils with the addition of several concentrations of the wild edible plants (WEP). For each vegetable oil ((a) sunflower, (b) olive, and (c) seed oil) data are the mean \pm SE of two determinations performed in three replicates and LSD values are shown.

concentrations of phenolics compounds, the major being derivatives of caffeic acid, apigenin, quercetin, and kampherol [12].

Thus, the aim of this work was to evaluate the effect of the addition of dry powder from three underutilised edible plants, fruits of Rosa canina, corn of Quercus ballota, and shoots and leaves of Sanguisorba minor to sunflower, seed, and olive oils on lipid oxidation during the frying process.

\section{Material and Methods}

2.1. Wild Edible Plants (WEP) and Vegetable Oils. Fruits of Rosa canina L., acorns of Quercus ballota Desf., and leaves of Sanguisorba minor Scop. were harvested at their optimum stage for consumption according to traditional practices and transferred to laboratory. Then, 3 homogeneous samples $(50 \mathrm{~g})$ were randomly performed for each species, 
which were frozen in liquid $\mathrm{N}_{2}$, lyophilized, and ground to be used as additives to vegetable oils. The vegetable oils used were virgin olive oil from oil press of Jaen (Spain), sunflower oil (Savena-Ibérica, Sevilla, Spain), and special seed oil for frying with increased oleic acid content and E900 antifoam (Hacendado, Mercadona, Spain). Samples of lyophilized WEP were added to the vegetable oils at $0.5,1$, and $5 \%(\mathrm{w}: \mathrm{v})$ and the vegetable oils were heated at $100^{\circ} \mathrm{C}$ for $12 \mathrm{~h}$. Experiments were performed in triplicate.

2.2. Lipid Peroxidation Measurement. Malondialdehyde (MDA) was quantified in duplicate in vegetable oils after the heating process as index of lipid peroxidation using the thiobarbituric acid reactive substrates (TBARS) assay [13]. Reaction mixture contained $1.5 \mathrm{~mL} 0.5 \%$ thiobarbituric acid (TBA) in $20 \%$ TCA and $0.5 \mathrm{~mL}$ of vegetable oil. The mixture was incubated at $90^{\circ} \mathrm{C}$ in a shaking water bath for $20 \mathrm{~min}$, and the reaction was stopped by placing the reaction tubes in an ice-water bath. The samples were then centrifuged at $1000 \mathrm{~g}$ for $5 \mathrm{~min}$, and the absorbance of supernatant was read at $532 \mathrm{~nm}$. The value for nonspecific absorption at $600 \mathrm{~nm}$ was subtracted. The amount of MDA-TBA complex (red pigment) was calculated from the extinction coefficient $155 \mathrm{mM} \mathrm{cm}^{-1}$ and expressed as mmol $\mathrm{MDA} \mathrm{g}^{-1}$ of vegetable oil. The data are the means \pm SE of quantifications made in duplicate in three replicates.

2.3. Statistical Analysis. Statistical analysis was performed by one-way analysis of variance (ANOVA). The results were calculated using the statistical software (SPSS, version 14.0, SPSS Inc., Chicago, USA). Least significant difference values (LSD; $P \leq 0.05$ ) were calculated to find significant differences among treatments.

\section{Results and Discussion}

Peroxides and hydroperoxides are products that represent the beginning of lipoxidation, a step in which the chainbreaker antioxidants can interrupt the process and restore the fatty acid chain [14]. Then, hydroperoxides are spontaneously decomposed to MDA, which can be used as an indicator of lipid peroxidation damage [15]. MDA concentration increased in vegetable oils after the heating process, with important differences among the vegetable oil, and the addition of WEP showed different effect depending on plant species and vegetable oils (Figure 1). Thus, in sunflower oil the concentration of MDA increased from initial values of $2.24 \pm 0.30 \mathrm{mmol} \mathrm{g}^{-1}$ to $6.53 \pm 1.63 \mathrm{mmol} \mathrm{g}^{-1}$ after the heating process, this increase being significantly reduced by the addition of the three WEP. Moreover, this effect was similar to the three plant species and the three used concentrations (Figure 1(a)) and could be attributed to the high phenolics content of these plants [8-11]. Accordingly, the addition of Nigella seed extract to this vegetable oil increased its oxidative stability [5]. Similar effects have been reported in soybean oil enriched with white tea and olive leaves extract, in which the oxidative extension during microwave heating was reduced [16].
However, in olive and seed oils the heating process had no significant effect on MDA content (Figures 1(a) and 1(b)), probably due to the high natural antioxidant compounds present in virgin olive oil, the most important being phenolic compounds (phenolic alcohols and acids, flavonoids, lignans, and secoiridoids), carotenes, and tocopherols [17, 18], and to the synthetic antioxidant added to the seed oil special for frying. Moreover, the addition of these WEP powders to olive oil was effective in reducing lipid peroxidation when added at $5 \%$, while at doses of 0.5 and $1 \%$ no significant effect was observed. Accordingly, the incorporation of rosemary, thyme, and lemon dried plants to olive oil just relatively helped to improve its thermal resistance [19]. On the contrary, in seed oil, the addition of WEP leads to different effect depending on plant species. Thus, MDA content decreased after the heating process with the addition of Quercus ballota corn, while the addition of increased concentration of Rosa canina fruit and leaves and shoots of Sanguisorba minor led to increases in MDA concentration, showing a prooxidant effect (Figure 1(c)). Other antioxidants have also different effects when added to different oils. Thus, TBHQ showed antioxidant effect in sunflower and soybean oils, while it displayed a prooxidant effect in corn oil [6].

Results show that the addition of dry powder of wild edible plants with high concentration of natural antioxidants could be an innovative and safety tool to increase thermal stability of vegetable oils such as sunflower, soybean, or corn and avoid or decrease the use of synthetic antioxidant.

\section{Conflict of Interests}

The authors declare that they have no conflict of interests.

\section{Authors' Contribution}

Ana Romojaro and Paloma Sanchez-Bel contributed equally to this work.

\section{References}

[1] M. D. Guillén and E. Goicoechea, "Toxic oxygenated $\alpha, \beta$ unsaturated aldehydes and their study in foods: a review," Critical Reviews in Food Science and Nutrition, vol. 48, no. 2, pp. 119-136, 2008.

[2] L. X. Qin, J. Chao, S. Yan, Y. M. Li, and C. X. Gang, "Analysis of synthetic antioxidants and preservatives in edible vegetable oil by HPLC/TOF-MS," Food Chemistry, vol. 113, no. 2, pp. 692700, 2009.

[3] E. D. Frankel, Antioxidants in Food and Biology. Facts and Fiction, The Oily Press, Bridgwater, UK, 2007.

[4] European Official Bulletin, BOE, (Order of 24 August 2007), BOE-A-2007-16339, http://www.boe.es/aeboe/consultas/bases datos/doc.php?id=BOE-A-2007-16339.

[5] F. Ammari, C. B. Y. Cordella, N. Boughanmi, and D. N. Rutledge, "The increase in oxidative stability of sunflower oil enriched with Nigella sativa L. seed extracts," Food Measure, vol. 6, pp. 12-20, 2012.

[6] A. Cordeiro, M. L. Medeiros, N. A. Santos et al., "Rosemary (Rosmarinus officinalis L.) extract: thermal study and evaluation 
of the antioxidant effect on vegetable oils," Journal of Thermal Analysis and Calorimetry, vol. 113, no. 2, pp. 889-895, 2013.

[7] C. M. Asensio, V. Nepote, and N. R. Grosso, "Chemical stability of extra-virgin olive oil added with oregano essential oil," Journal of Food Science, vol. 76, no. 7, pp. S445-S450, 2011.

[8] L. Barros, A. M. Carvalho, and I. C. F. R. Ferreira, "Exotic fruits as a source of important phytochemicals: improving the traditional use of Rosa canina fruits in Portugal," Food Research International, vol. 44, no. 7, pp. 2233-2236, 2011.

[9] I. Egea, P. Sánchez-Bel, F. Romojaro, and M. T. Pretel, "Six edible wild fruits as potential antioxidant additives or nutritional supplements," Plant Foods for Human Nutrition, vol. 65, no. 2, pp. 121-129, 2010.

[10] A. Romojaro, M. A. Botella, C. Obón, and M. T. Pretel, "Nutritional and antioxidant properties of wild edible plants and their use as potential ingredients in the modern diet," International Journal of Food Science and Nutrition, vol. 64, no. 8, pp. 944-952, 2013.

[11] E. Cantos, J. C. Espín, C. López-Bote, L. de la Hoz, J. A. Ordóñez, and F. A. Tomás-Barberán, "Phenolic compounds and fatty acids from acorns (Quercus spp.), the main dietary constituent of free-ranged Iberian pigs," Journal of Agricultural and Food Chemistry, vol. 51, no. 21, pp. 6248-6255, 2003.

[12] M. A. Gatto, A. Ippolito, V. Linsalata et al., "Activity of extracts from wild edible herbs against postharvest fungal diseases of fruit and vegetables," Postharvest Biology and Technology, vol. 61, no. 1, pp. 72-82, 2011.

[13] R. L. Heath and L. Packer, "Photoperoxidation in isolated chloroplasts. I. Kinetics and stoichiometry of fatty acid peroxidation," Archives of Biochemistry and Biophysics, vol. 125, no. 1, pp. 189-198, 1968.

[14] F. Shahidi and Y. Zhong, "Lipid oxidation and improving the oxidative stability," Chemical Society Reviews, vol. 39, no. 11, pp. 4067-4079, 2010.

[15] S. Y. Rogiers, G. N. M. Kumar, and N. R. Knowles, "Maturation and ripening of fruit of Amelanchier alnifolia Nutt. are accompanied by increasing oxidative stress," Annals of Botany, vol. 81, no. 2, pp. 203-211, 1998.

[16] R. Malheiro, N. Rodrigues, G. Manzke, A. Bento, J. A. Pereira, and S. Casal, "The use of olive leaves and tea extracts as effective antioxidants against the oxidation of soybean oil under microwave heating," Industrial Crops and Products, vol. 44, pp. 37-43, 2013.

[17] D. L. García-González, R. Aparicio-Ruiz, and R. Aparicio, "Virgin olive oil-chemical implications on quality and health," European Journal of Lipid Science and Technology, vol. 110, no. 7, pp. 602-607, 2008.

[18] M. Servili, S. Esposto, R. Fabiani et al., "Phenolic compounds in olive oil: antioxidant, health and organoleptic activities according to their chemical structure," Inflammopharmacology, vol. 17, no. 2, pp. 76-84, 2009.

[19] M. A. Ayadi, N. Grati-Kamoun, and H. Attia, "Physico-chemical change and heat stability of extra virgin olive oils flavoured by selected Tunisian aromatic plants," Food and Chemical Toxicology, vol. 47, no. 10, pp. 2613-2619, 2009. 

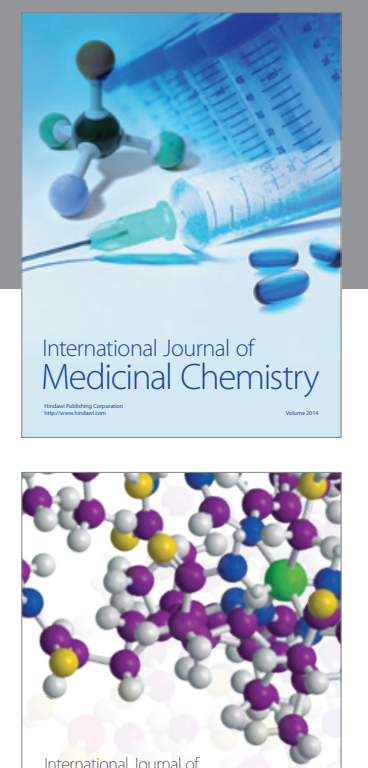

\section{Carbohydrate} Chemistry

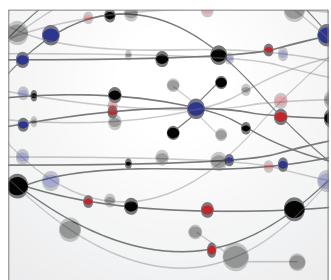

The Scientific World Journal
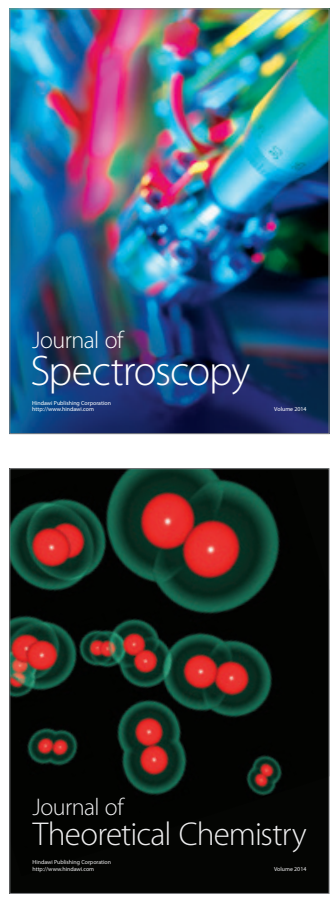
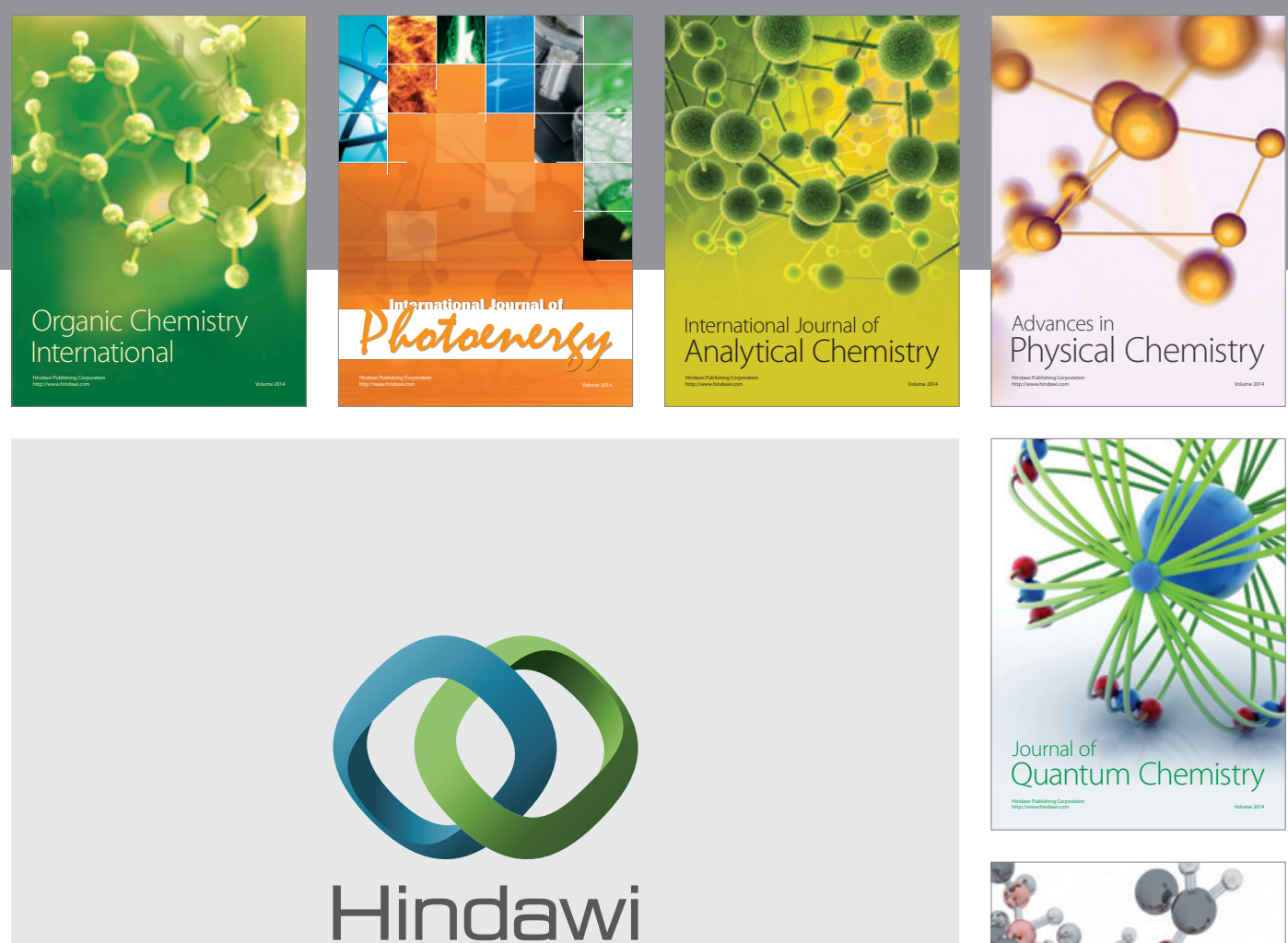

Submit your manuscripts at

http://www.hindawi.com

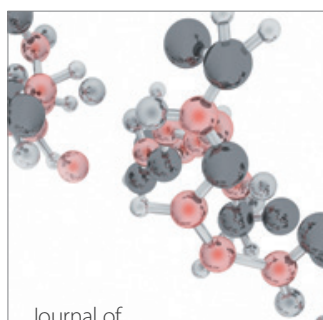

Analytical Methods

in Chemistry

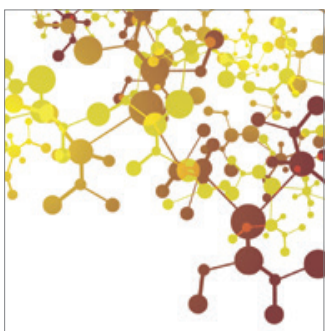

Journal of

Applied Chemistry

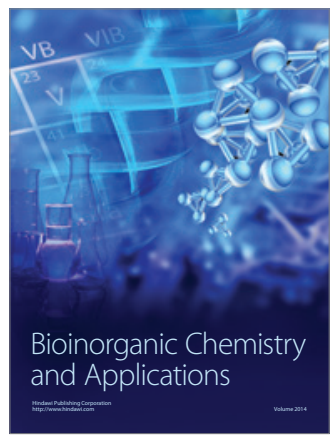

Inorganic Chemistry
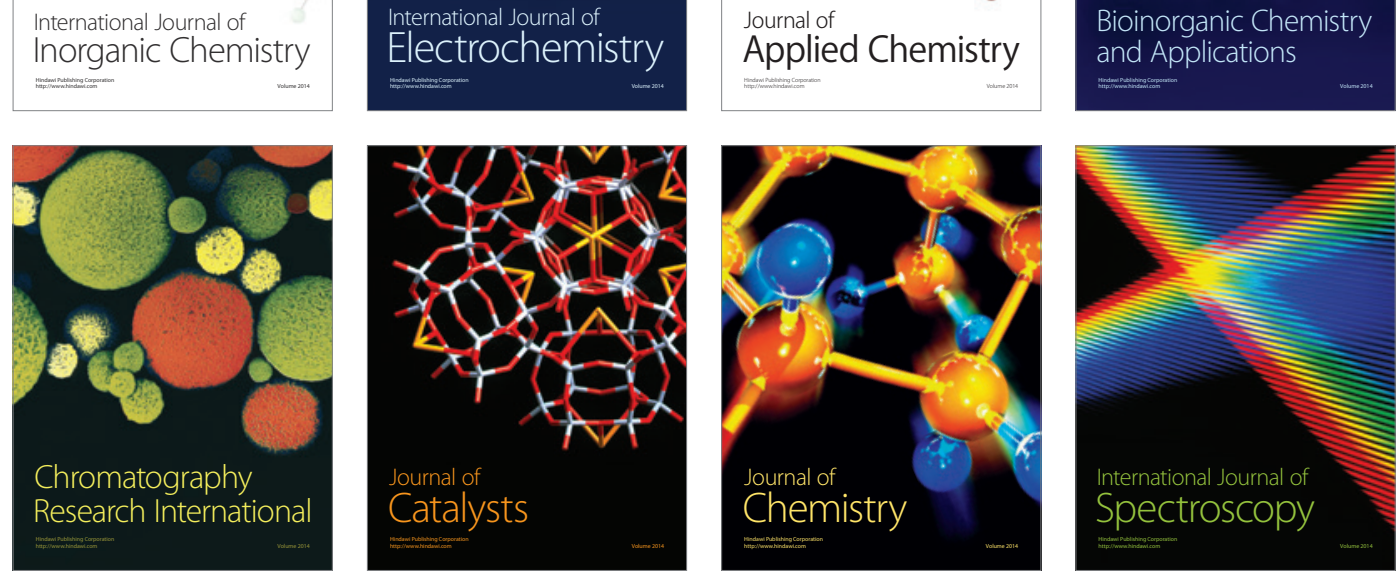